\title{
Research on Tourism Driving the Development of the Tertiary Industry
}

\author{
Xinyi Deng*
}

\author{
Beijing Jiaotong University, China \\ *Corresponding author. Email: dxy19990205@163.com
}

\begin{abstract}
The tourism industry has gradually become an important part of the development of my country's service industry. Through the analysis of the characteristics of the tourism industry and the characteristics of the tertiary industry, the article derives the association mechanism between the tourism industry and the tertiary industry. To promote the development of the tertiary industry, we must first formulate a long-term development policy, and secondly expand the domestic and foreign tourism market, and optimize the structure of the tertiary industry.
\end{abstract}

Keywords: Tourism, Tertiary industry, Relevance, Leading role.

\section{INTRODUCTION}

In recent years, the development of China's tourism industry has embarked on a fast track. As of the end of 2018, the number of domestic tourists reached 5.54 billion, domestic tourism revenue reached 5,127.8 billion yuan, foreign exchange income from tourism reached 127.1 billion US dollars, and the added value of the tertiary industry was 4, 69575 billion With an average annual growth rate of $12 \%$ in total tourism revenue, it has become an important part of my country's service industry. Through its six elements of "food, lodging, travel, shopping and entertainment", the tourism industry has indirectly affected other industries such as the accommodation and catering industry, transportation and postal industry, wholesale and retail industry, real estate industry, financial industry, etc. It has become an improvement in the economic structure, promoting economic growth, and driving Domestic demand, increasing employment opportunities, increasing taxation and other important breakthroughs in the national economy, the leading role of tourism in the development of the tertiary industry cannot be underestimated. This article hopes to put forward good suggestions for the development of the two by analyzing the development characteristics and related mechanisms of the two.

\section{CHARACTERISTICS OF THE TOURISM INDUSTRY}

According to the statistics of the China Tertiary Industry Statistical Yearbook, in 2017, China received $139,482,400$ inbound tourists, an increase of $0.8 \%$ over the previous year. Among them, 29,165,300 were foreigners, an increase of $3.6 \%$ over the previous year. International tourism revenue was USD 123.417 billion, which was an increase from the previous year. An annual increase of 2.8\%. From 2014 to 2017, the added value of the tourism industry has climbed for three consecutive years, from 2743.3 billion yuan to $3,297.9$ billion yuan, and its share in the total GDP rose from $4.26 \%$ to $4.44 \%$, becoming an important strategic pillar industry in China.

Tourism is a globally recognized "sunrise industry" with broad prospects and huge development potential, and has many advantages.

First, tourism is a comprehensive industry with multiple attributes. According to traditional theories, the six major elements of the tourism industry are "eating, housing, transportation, travel, shopping, and entertainment". Enterprises achieve the goal of profit by satisfying the consumption needs of tourists. The activities are connected, each providing products and services, and working together as a supplier to become an integrated whole. At the same time, the products provided by these tourism industries are also a comprehensive whole, including tangible and intangible 
products, such as tourism reception service facilities, hotels, restaurants, shopping malls, entertainment venues, etc., which are industries within the scope of economic activities, and In order to satisfy tourists to rest and enjoy the cultural services provided. Therefore, a significant feature of the tourism industry is the integration of cultural and economic attributes. The development of tourism is a multi-sectoral coordinated activity, which has promoted the development of industries such as agriculture, forestry, animal husbandry, fishery, trade, processing and manufacturing in tourist destinations, and even spawned new industries, such as cultural performances. The comprehensive analysis of tourism and other industries is conducive to providing consumers with better products.

The second is the popularization of tourism service targets. As modern people gradually have the prerequisites for tourism, economic and social development, increased per capita disposable income, and sufficient leisure time, the popularization of tourism is reflected in the increase in the number of tourists, the increase in the number of trips, the increase in travel distance, and the increase in tourism expenditure etc. This also puts forward requirements for operators. Tourism is not only a consumption field for the wealthy, but the participation of the broad masses of people requires the parity of tourism products, the humanization of tourism services, and the diversification of tourism facilities and projects.

Third, the tourism industry is an intensive modern service industry. Service is an intangible product that is invisible and intangible. The tourism industry is mainly to provide this product. In the consumption process, the quality of the service and the quality of the service can only be evaluated through the consumer's own feelings, and made Evaluation. This determines that in the degree of relevance between tourism and the three industries, the relationship with the tertiary industry is the closest. It not only involves consumer services, but also includes production services, circulation services, and social services. It integrates labor-intensive, capital-intensive, and knowledge-intensive industries. It has a full effect on all fields and links of social production, and its contribution to increasing employment is obvious to all. Therefore, the development of the tourism industry must not only rely on high-quality tourism resources, but also be supported by a strong national economy. After years of development, China's tourism industry has shown the characteristics of medium-term input and medium-output. With input and high output, it is necessary to accelerate the integration of tourism and service industry, and to integrate with international standards as soon as possible. Tourism plays a decisive role in my country's economic development.
Fourth, the tourism industry is strongly related to other industries. The production and consumption of the tourism industry are at the same time. As long as there is consumption of tourists, the demand for tourism will follow. According to the UNWTO (World Tourism Organization) report, tourism is the third largest consumer item in the world after food and accommodation. However, due to external force majeure, tourism demand will be greatly impacted. At the beginning of 2020, my country was affected by the COVID-19, and the tourism industry was completely suspended. Most governments and institutions are expected to be affected by the epidemic, and China's tourism market will have an impact of at least 500 billion yuan. According to the trend of the spread of the epidemic abroad, The loss may exceed 1.2 trillion yuan. However, the sensitivity of the tourism industry to the crisis also shows another characteristic of counter-cyclical development. After the "SARS" epidemic in 2003, "retaliatory consumption" appeared in the tourism market, and the tourism industry recovered quickly in a short period of time, making it the industry with the fastest recovery in consumption hotspots. This proves that the tourism industry is a sunrise industry with a high degree of relevance, strong driving force and high vitality.

\section{CHARACTERISTICS AND DEVELOPMENT TREND OF THE TERTIARY INDUSTRY}

Compared with the primary and secondary industries, the tertiary industry has significant characteristics.

First of all, the tertiary industry itself does not create material products, but some of its sectors can add value to products, such as commerce and transportation, which are called productive (cargo) services, and other sectors such as state agencies are for the public the provision of various services is called non-material services.

Secondly, the tertiary industry does not have an independent physical product form, and its production activities generally do not change the main nature and form of the original product, but increase the value of the goods through the transformation of the spatial location of the goods, or provide non-material services to realize the value of their services.

Third, the labor objects of the tertiary industry are extensive. The so-called universality means that the objects of labor in some sectors can be determined, such as commerce, where the objects of labor are commodities, while the objects of labor in other sectors are impossible and unnecessary to determine one by one. It can only be said to be for social development. 
And the satisfaction and improvement of people's living standards, such as public utilities and consulting.

Various services provided by the tertiary industry are generally completed at the same time as people use services. For example, the sale of goods in a store means the beginning of people's consumption of goods.

From the early days of the founding of the People's Republic of China to the 1970s, China was under a planned economic system, and the development of the tertiary industry was relatively slow. Most enterprises adopted self-enclosed production and management, which greatly restricted the development of the service industry. After the reform and opening up, the economy gradually shifted to market orientation. From the 1980s to the 1990 s, in just ten years, the added value of the tertiary industry rose from $21.4 \%$ to $31.3 \%$ of the total GDP, with an average annual growth rate of $12.3 \%$. Higher than the growth rate of GDP. Today, my country's tertiary industry mainly shows the following development trends:

First, the added value of the tertiary industry as a proportion of GDP is on the rise. In 2017, it exceeded $50 \%$, an increase of 17 percentage points from 1994. But on the whole, the development of China's tertiary industry lags behind other countries in the world, and is far from the average level of $70 \%$ in developed countries, and has great potential for development. Second, the tertiary industry has become an important force in absorbing labor. According to the "Statistical Yearbook of China's Tertiary Industry", the total number of employees in the whole society in 2017 was 776.4 million, the primary industry was 20.44 million, and the secondary industry was 21.24 million. The number of people in the tertiary industry is 348.72 million, and the employment in the tertiary industry accounts for $44.9 \%$ of all employees, which has continued to grow steadily and surpassed the primary and secondary industries. Third, the internal structure of the tertiary industry is low and regional development is uneven. China's tertiary industry is mainly based on traditional service industries and commerce, which are labor-intensive industries, while high-level knowledge-intensive industries such as computer and software industries, financial industries, and scientific research account for a relatively low proportion. "The industrial structure is far away. Due to China's vast territory and uneven regional development levels, there are huge differences in urban-rural and regional development, from coastal to inland, from urban to rural areas, showing obvious level differences. On the whole, the contribution rate of China's tertiary industry to China's economic growth has increased significantly, the industrial structure will continue to be improved, and regional development will be more balanced.

\section{TOURISM AND TERTIARY INDUSTRY LINKAGE MECHANISM}

In industrial economics, there is the theory of industrial linkage, that is, the theory of industrial linkage, which mainly analyzes the relationship between industrial input and output. In recent years, foreign academic circles have proposed the concept of industrial integration and integration. The English dictionary is officially translated as "Integrate", which refers to the integration of various industries and industries to form a whole. With the continuous expansion of the tourism industry, the continuous extension of the chain, and the continuous expansion of the market, the integration and development of tourism and the tertiary industry has become a general trend. Tourism and the tertiary industry include wholesale and retail, transportation, information transmission, software and Information technology service industry, financial industry, leasing and business service industry, education, culture, sports, and entertainment industries will drive each other's development, and eventually will go to the trend of integration and even emerge a new business format.

The core sectors of the tourism industry include industries that directly provide tourists with food, accommodation, transportation, travel, shopping, entertainment and other tourism products and services. Various sectors of the tertiary industry, including transportation and postal industry, accommodation and catering, wholesale and retail, finance, real estate, and other industries, six types of industry sectors. These sectors provide tourists with travel needs to meet their travel needs. Direct or indirect service products. It constitutes a strong economic and cultural support for the tourism industry. Therefore, the core industry of tourism affects the development of all levels of the tertiary industry. At the same time, the secondary prosperity of the tertiary industry in turn restricts the development of the tourism industry. Tourism and the tertiary industry are closely related and mutually driven, forming a huge industrial cluster.

\section{COUNTERMEASURES AND SUGGESTIONS TO PROMOTE THE DEVELOPMENT OF THE TERTIARY INDUSTRY WITH TOURISM}

\subsection{Formulate Long-term Development Policies}

When formulating tourism development plans, the government must take into account the long-term stable and balanced relationship between domestic tourism development, international tourism development, and the tertiary industry. From a long-term strategic perspective, formulate long-term plans. Right now, it is necessary to establish a long-term mechanism for the 
development of tourism, and make continuous adjustments in accordance with the actual development of the domestic tourism industry, with flexibility.

\subsection{Expanding the Domestic and Foreign Tourism Market}

Tourism is a special economic industry. It has penetrated into all economic sectors in our country. In order to develop tourism well, it is not enough to rely on the government alone. It is also necessary to rely on the "invisible hand" of the market to break different industries across regions. It advocates "whoever invests, who benefits", so that the country, enterprises, and individuals can participate in the development of the market, raise funds, and realize the diversification of investment entities to develop my country's tourism market. In China's tourism market, the domestic tourism market is rich in resources and large in demand. In order to protect this part of the market, it is necessary to strengthen the construction of infrastructure, improve the phenomenon of "dirty, chaotic, and poor" tourist places, and focus on strengthening construction projects and improving services Level and reception level to better meet the needs of tourists. At the same time, taking into account the international market, expanding the level of opening up, and enhancing international competitiveness. For leading domestic and foreign tourism companies, we must focus on cultivating and developing, and comprehensively deepen reforms. China's tourism companies are small in scale and loosely managed. They can achieve intensive operation through alliances, acquisitions, and shareholdings with major foreign tourism companies, and expand their scales. Connect well with the world, realize the two-way development of the domestic and foreign tourism markets, and build a new development pattern in which the domestic and international double cycles promote each other.

\subsection{Optimize the Structure of the Tertiary Industry}

The development of China's tourism industry mainly depends on the development of the tertiary industry, and China's tertiary industry still has a large development space, the industrial structure is low, and new economic growth points need to be cultivated. The tourism industry has many high-quality features, which can absorb labor, increase employment, improve the overall quality of employment in the tertiary industry, and connect with the development of key sectors of the tertiary industry such as transportation, catering, hotel accommodation, cultural and performing arts It is very close. It is necessary to strengthen the coordination and cooperation between the tourism industry and these departments, extend the tourism industry chain, promote the rationalization of the internal structure of the tertiary industry, and transform from the traditional service industry to the modern service industry. This requires us not only to win in terms of quantity, but also to optimize and upgrade the industrial structure in terms of quality and structure, to modernize tourism products, to strengthen alliances with e-commerce, to break down industrial, agricultural, and commercial barriers, and to use diversified applications. The platform realizes the production, supply and sale of tourism products, develops production service industries such as logistics, transportation, and information, and promotes the modernization of the tertiary industry. The prosperity of tourism promotes the development of the tertiary industry, improves the status of the tertiary industry in the national economy, and further realizes economic growth and optimization and upgrading of the industrial structure.

\section{CONCLUSION}

Tourism is an important part of China's service industry. Through the analysis of the characteristics of tourism, it is concluded that tourism is a comprehensive industry with multiple attributes. Its service targets are popular, and it is an intensive modern service industry, which is related to other industries. And through analysis, it is concluded that the tertiary industry is different from other industries in that the tertiary industry does not create material products, does not have an independent physical product form, and the labor objects are extensive. And presents the following development trends. First, the proportion of the tertiary industry's added value in the gross national product is on the rise. Secondly, the tertiary industry has become an important force in absorbing labor, but the internal structure of the tertiary industry is low and the regional development is not balance. Establish a related mechanism between the two and put forward suggestions on formulating long-term development policies, expanding domestic and foreign tourism markets, and optimizing the structure of the tertiary industry to promote the tourism industry to better promote the development of the tertiary industry.

\section{REFERENCES}

[1] Granger, C. W. J. Investigating causal relations by Econo-Metric Models and Cross-spectral Methods. Econometri-ca, 1969, 37(3): 424-438.

[2] Pizam M A.Social impacts of Tourism of Central Florida. Annals of Tourism Research, 1983, 15(2): 191-204.

[3] Fletcher J E, Snee H R. The Service Industries and In-Put-output Analysis. Service Industries Review, 1985, 2(1): 51-79. 
[4] Kottke M W. Estimating Economics Impacts of Tourism. Annals of Tourism Research, 1988, 15(1): 122-133.

[5] Archer B, Fletcher J. The Economic Impact of Tourism Inthe Seychelles. Annals of Tourism Research, 1996, 23(2):45-48.

[6] Getz D. Event Management Event Tourism. New York: Cognizant Communication Corporation, 1997: 341 .
[7] Su Jianjun, Sun Gennian, Wang Lifang. Analysis of the Correlation driving force of China's tourism industry to the tertiary industry since 1982 [J]. Advances in geographical science, 2011, 30(08):1047-1055. (in Chinese)

[8] Hooper. Empirical Analysis of the relationship between inbound Tourism and tertiary industry development in Anhui Province [J]. Heilongjiang Foreign Trade and Economic Cooperation, 2011(07):138-139. (in Chinese) 